\title{
Weaving First Peoples' Knowledge into a University Course
}

First Peoples' knowledge at university lies within a contested knowledge space. The incompatibilities and differences between Western and First Peoples' knowledge systems means attempts to superficially 'add' First Peoples' content to university courses are often ineffective and tokenistic. Considering these issues, this article reflects on the design and implementation of weaving First Peoples' knowledge and perspectives throughout a service-learning course. The course is a nationally awarded work-integrated learning program delivered to undergraduate and postgraduate students. Drawing on a theoretical framework of Woven Law, the design of the module was led and authored by First Peoples. Throughout the design process, the module was critically examined in terms of the content developed and methods of content inclusion, while also responding to institutional demands of student learning outcomes. Survey results show a positive student reception and early success in enabling students to achieve learning outcomes. While initial results are promising, data is limited due to this being the first assessment of the program and the fact that students were asked to rate their own experience. Nonetheless, Woven Law and carefully weaving First Peoples' knowledge throughout the curriculum represents a promising methodology and area for future research.

This paper explores a holistic approach to weaving First Peoples' knowledge and perspectives throughout an experiential learning curriculum led and authored by First Peoples. This paper first explores the issues associated with attempts to 'add' First Peoples' perspectives to existing curricula. Based on notable gaps in both research and practice, the research team sought to conceptualise an approach to integrating First Peoples' knowledge as an essential 
part of course design for experiential learning. This paper outlines the development of a First Peoples' module for the Community Internship (CI) course at Griffith University. The course is a nationally awarded work-integrated learning (WIL) program delivered to undergraduate and postgraduate students across most disciplines. The CI course has a specific focus on community, enabling students to engage with a theoretical understanding of community while also developing their knowledge and understanding through WIL.

The research problem was identified through engagement with the literature and firsthand experiences of the research team. A course content review provided an opportunity to create space for First Peoples knowledge and perspectives within the course. Given the issues associated with 'adding' First Peoples' knowledge and perspectives to curricula (Nakata, Nakata, Keech and Bolt, 2012; Collins-Gearing and Smith, 2016), an innovative approach was employed to closely interweave First Peoples' knowledge and perspectives throughout the course enabling First Peoples' methodologies to inform course design itself. Having discussed the literature around superficial inclusion of First Peoples in curricula, this paper then introduces Woven Law as the methodological approach to the design and implementation of the research project. This paper then discusses the CI course as the research site before moving on to the design process of the First People's module. The paper explains that the approach to designing the content and learning module was aimed at being responsive to concerns from earlier attempts to 'Indigenise' the curriculum (Nakata et al, 2012; Howlett, Ferreira, Seini and Matthews, 2013; Collins-Gearing and Smith, 2016). This paper then outlines how the module was developed according to First Peoples' terms of reference and how the research team believed it was important to not only teach First Peoples' content, but to do so according to a First Peoples' pedagogy.

This paper concludes by presenting the results of a survey about the student experience of the First Peoples' module. Initial survey results show a positive student 
reception and early success in enabling students to achieve their learning outcomes. ${ }^{1}$ While initial results are promising, data is limited by the survey being the first assessment of the program and the fact that students were asked to assess their own experience and were not measured by a competency-based or more substantial or otherwise designed model of review. The broader aim of this research project is to further develop this module to become a guide for others wishing to include and teach First Peoples' knowledge and perspectives.

\section{Navigating "contested knowledge spaces"}

Much has been written about the complex place of First Peoples' knowledge within the Western academy. Martin Nakata (2007) refers to these complex places where different knowledge systems meet as "contested knowledge spaces". The contested nature of these spaces is emphasised by Russell (2005), who observes that Western and Indigenous knowledges are increasingly seen as separate and incompatible. The work of Nakata, however, reminds us of the inherent complexity of such spaces, where things are "not clearly black or white, Indigenous or Western" (2007, p. 9).

\footnotetext{
${ }^{1}$ Learning outcomes of the CI course include being able to understand citizen involvement in community organisations, be able to critically appraise the role of volunteering to the internship organisation, critically appraise personal and professional skills, and to demonstrate a range of employability skills.

The CI course is also aimed at assisting students to achieve Griffith University's Graduate Attributes. Specifically, Graduate Attribute 5 requires students to be 'Culturally capable when working with First Australians'. This is explained as:

In order to be culturally capable when working with First Australians, staff (academic and general) and students must have:

A. An understanding of Aboriginal and Torres Strait Islander peoples, histories, cultures and identities

B. An understanding of Aboriginal and Torres Strait Islander peoples achievements and visions

C. The ability to work skillfully and purposefully with First Australians and communities in professional contexts.
} 
Indeed, there is no singular definition of First Peoples' knowledge. First People's knowledge and perspectives are as varied and as different as are the people, communities, cultures and traditions themselves. These differences are informed by differing historical and contemporary circumstances of colonialism and other issues related to the different, but in many ways, similar experiences, of First Peoples. It is important to understand however that while recognising the role of colonial and other influences on First Peoples, communities and knowledges, that First Peoples themselves have not been passive bystanders in this process, and that Indigenous knowledges are a living and changing product of this encounter and their own cultures and traditions.

Limited generalisations however for the purpose of heuristic instruction can be made of 'Indigenous knowledge'. This includes introducing students to First Peoples' perspectives and worldviews such as Indigenous (general and specific) laws, cultures, traditions and histories, and how these mattes inform the lives of individuals and communities (Battiste and Henderson, 2009; Nakata et al, 2014). What is important in approaching the inclusion of Indigenous knowledge and experience however isn't necessarily the content that is taught, but rather the practice and process of teaching itself which must embody and practice First Peoples' ways of knowing and learning (Rigney, 2012; Nakata et al, 2014). This represents a distinct challenge for universities and institutions more familiar with Western knowledge systems and as institutions that have historically played important roles in the exclusion and denial of Indigenous peoples (Rigney, 2012; Pridham, Martin, Walker, Rossengren and Wadley, 2015).

Efforts by institutions in response to these issues to simply 'add' First Peoples' knowledge and content to courses and teaching have tended to be simplistic at best, and tokenistic at worst. Nakata et al (2014) further explain that limited additions of Indigenous content through simplistic embedding practices has served to limit educational possibilities 
rather than enhance them. Explaining these limitations and their implications further, Giovanangeli and Snepvangers (2016) observed in their survey of non-Indigenous Australian tertiary educators a reluctance and inability of educators to engage with Indigenous topics through their teaching, resulting from confusion about how to embed such complex knowledge systems within their curriculum. Therein lies a compounding problem. Rather than simply pitting 'Western' philosophies and worldviews against 'Indigenous', the focus must be beyond presenting static factual information or content that may conform to traditional knowledge and power relationships between Indigenous peoples and educational institutions (Carlson and McGloin, 2013; Nakata et al, 2014; Carey, 2015).

This approach to Indigenous knowledges better develops and understands the required deeper connections according to the relational nature of First Peoples' cultures and traditions (Graham, 2008; Grieves, 2008; Black, 2011; Hollinsworth, 2013; Graham, 2014). As Nakata explains: "it is not possible to bring in Indigenous knowledge and plonk it in the curriculum unproblematically as if it is another data set for Western knowledge to discipline and test" (2007, p. 8). Indeed, taking into account First Peoples' epistemologies in both methods and content offers a relevance that cannot be achieved through simply trying to fit First Peoples' culture into Western pedagogies and curricula (Riley, Howard-Wagner and Mooney, 2015). There have been many critiques of the incorporation of First Peoples and knowledges into Western institutions, especially within education institutions, that support this (Nakata, 2007; Smith, 2012; Rigney, 2012; Watson, 2014). This critical work has asked key questions about:

- The nature and form of Indigenous content and knowledge in Indigenous studies program areas and more broadly across the university curriculum (Henderson, 2005; Battiste and Henderson, 2009; Smith, 2012; de Oliveira Adreotti, Stein, Ahenakew and Hunt, 2015; Gilbert and Tillman, 2017); 
- The method of the delivery of Indigenous content across Indigenous studies programs and the university curriculum. Particular attention being paid to ensure content is not simply added, but is rather placed appropriately and delivered or made available in ways that enable First Nations theoretical frameworks (Carey, 2015; Heckenberg, 2015; Gilbert and Tillman, 2017);

- Whether these inclusions and studies simply repeat and therefore re-legitimate non-Indigenous knowledge and perspectives at the expense of First Nations peoples and communities (Martin and Mirraboopa, 2003; Nakata, 2018);

- And whether there are any tangible outcomes for First Nations peoples and communities through developing engaged and effective partnerships, committing responsibly to the obligations of relational being.

These critiques provide a valuable framework for shaping an approach that enables Indigenous knowledges and perspectives to be produced, understood and preserved together by students, staff and the community by engaging in dialogical and reflective education that can be designed to avoid the pitfalls and repetitive mistakes of 'inclusion' and 'addition'.

\section{Woven Law}

Woven Law is a narrative metaphor that has been adapted to represent and encourage students to build deeper understandings of other peoples and their selves through critical, reflexive, and dialogical encounters with First Peoples' knowledge and perspectives. ${ }^{2}$ This research project utilises Woven Law as a socio-legal approach to understanding First Peoples' history and experiences of the law - read more broadly as experiences of society itself - as they

\footnotetext{
${ }^{2}$ Woven Law is adapted from the doctorate research and practice of Edward Synot in partnership Sharon Mununggurr. Woven Law is based in the history, traditions and experiences of the Wamba Wamba people near Deniliquin New South Wales coming from the communities of Moonahcullah, Deniliquin and Cummeragunja.
} 
become woven into Indigenous lives, but that also bases its understanding and development in Indigenous ontologies of being. Woven Law is not simply about First Peoples' knowledge but is envisioned as a framework developed according to First Peoples' theoretical frameworks available to all peoples to make sense of their experiences and communities. By not only including, but also teaching, First Peoples' knowledge through weaving, the research team aimed to ensure the practice and learning of First Peoples' knowledge not only continues as it has done since time immemorial but that it is not compromised by 'inclusion'.

Woven Law helps to orientate ourselves within our experiences and communities and is built on the practice of weaving as a fundamental practice in many First Peoples' cultures and traditions. Weaving is key to the simultaneous maintenance and production of life and order according to First Peoples' cultures and traditions (Ingold, 2000; Tjanpi Desert Weavers, 2015; Biana, 2017). The relational character at the centre of First Peoples' knowledge is both a representation of First Peoples' culture and a narrative metaphor to represent the production of knowledge and culture itself that is shared around the world by First Peoples (Mignolo, 1999; Battiste and Henderson, 2009; Black, 2011; Smith, 2012; Watson, 2014).

The importance of this relational orientation through Woven Law is represented by the practice of collecting grasses and materials used in weaving. This practice situates First Peoples within their environments as relational beings, grounded in their place-based relational knowledge (Graham, 2008; Black, 2011; Graham, 2014; Heckenberg, 2015). It is this placement in relation with others that is representative of the laws, obligations and responsibilities of First Peoples and communities, rather than any static, unchanging or essential characteristic of First Peoples' culture. Key here is that rather than any static or piecemeal idiom of culture that too often (mis)represents First Peoples, this relational placement as an approach to knowledge production and preservation remains authentically 
Indigenous. This approach, adaptive and flexible, can be understood as central to representing and understanding First Peoples' knowledges and to overcoming issues with the generalisation of First Peoples' culture and traditions for heuristic purposes. According to this relational base, First Peoples' cultures, knowledge and perspectives are brought to life through their varied practices and are maintained by this same living structure of relations. They are lived and constantly adapting, demanding responsible action and response, to the changing world around them.

The importance of weaving is further illustrated by the life, social and cultural endeavours supported by woven objects in First Peoples' cultures and traditions. These include objects and social institutions such as vessels for carrying children, food, clothing and shelter. Weaving is a key action that binds and layers First Peoples and communities in diverse ways. The weave connects and holds people and place together, but in differential, and sometimes incongruent ways, allowing for those binds and layers to be rediscovered, reproduced and healed. The weave, like First Peoples and communities, is not easily destroyed due to its layered and interwoven nature in the sense that separate binds or weaves touch and relate to one another, holding together peoples and communities in their differences and experiences, producing and maintaining patterned and relational beings and tying them through their obligations and responsibilities to one another.

This approach enables Indigenous knowledges and perspectives to be understood and preserved together by students, staff and the community by engaging in dialogical and reflexive education through woven practice. ${ }^{3}$ Woven Law not only describes but also facilitates education and understanding of this process to assist in developing deeper understandings of First Peoples' knowledges through encounters with First Peoples,

\footnotetext{
${ }^{3}$ This practice is explained below through the development of Woven Law and the First Peoples' Module.
} 
communities, cultures, histories and traditions. This approach to First Peoples' knowledges enables responsible engagements through the realisation and maintenance of relational being. This approach is developed beyond the deficit approach of represented socioeconomic gaps between Indigenous and non-Indigenous peoples that is often the focus of social-justice approaches to First Peoples' knowledge and perspectives.

\section{Weaving in the Community Internship course}

The CI course is an award-winning WIL program. The course is available to undergraduate and masters level students throughout the year. Students from all disciplines are eligible to enrol in the CI course as a free choice elective however some students must complete the CI course as a core requirement. The majority of enrolments continue to be students that have chosen the CI course as a free-choice elective. The CI course is structured in two parts. The first is an academic course with lectures, workshops and assessments. The second is a voluntary internship of 50 to 80 hours of community work with a Community Partner. The course is methodologically organised according to a WIL program that scaffolds and develops reflective student learning as the course progresses. The internship progresses alongside the academic component, allowing students to learn in a dialogically reflexive environment that provides multiple opportunities for student understanding to be assessed and affirmed.

Given the widely applicable nature of the course content across all communities, the CI course was identified as a suitable site to address the inclusion of First Peoples' knowledge and perspectives and to enable students to achieve Griffith University's Graduate Attribute 5 to be culturally capable when working with First Australians. Furthermore, First Peoples have been historically marginalised and excluded from greater participation in the community and have important contributions to make based both in their own traditions and cultures and through this experience of marginalisation and exclusion (Mignolo, 1999; Nakata, 2007; 
Mignolo, 2011; McKnight, 2016; Kwaymullina, 2016). Beyond this, however, and most importantly for the research team, First Peoples have their own legitimate worldviews and terms of reference that represent legitimate ways of knowing, being and doing. The research team took the view that First Peoples' knowledge and perspectives are valid and should be included on this basis alone, rather than any need to overcome any specific or general socialjustice concerns.

The CI course also provides opportunity for student engagement with First Peoples through their work with CPs. Further to this, the CI course includes students from most discipline backgrounds enabling a broad influence across the student body. The CI course structure is further complementary to an alternative assessment and content structure to be developed that enabled the flexible development and inclusion of First Peoples' theoretical frameworks. This meant that rather than 'adding' First Peoples' content as a one-off topic, First Peoples' knowledge and perspectives were able to be woven throughout the course program, directing the CI course itself and informing assessment evaluation. This provided students with an opportunity to engage with First Peoples' knowledge and perspectives in a dialogical and reflexive manner at multiple stages of their development. Further, the assessment reflects the place-based knowledge and a woven practice where students are facilitated through the development of practical understandings of relational being. ${ }^{4}$

\section{The First Peoples' Reference Committee}

Given the issues identified in the literature and those that emerged from previous experiences of 'Indigenising' or 'decolonising' course content, the CI teaching team sought to embed First Peoples' knowledge and perspectives through a process that was authored and directed by

\footnotetext{
${ }^{4}$ Detailed below in the First Peoples' Module section.
} 
First Peoples. To achieve this, a First Peoples' Reference Committee consisting of traditional owners, members of the Griffith University Council of Elders and other Indigenous academic staff was established as a way of creating space for First Peoples to authorise and lead the decision-making process beyond inclusion.

The research team first approached Uncle John Graham, a member of the Griffith University Council of Elders. Uncle John is a Kombumerri traditional owner from the Gold Coast who has worked in Indigenous higher education support for over 15 years. It was important to not only have First Peoples guiding this process but to also specifically have traditional owners of the country from which the team were working on as key members of the team. Following the approach to Uncle John, the teaching team were joined by Associate Professor Mary Graham, a Kombumerri traditional owner and legal scholar, and Indigenous academic lawyer and researcher Edward Synot.

The Reference Committee set about discussing what was the best way forward for including First Peoples' knowledge and perspectives in the CI course. No time constraints were imposed on this process with discussion and planning developing organically, foregrounding First Peoples' knowledge, perspectives and experience with regard to placebased and relational knowledge. ${ }^{5}$ The Reference Committee agreed to ensure that everything the committee did, from the way it conducted its meetings to the work that it produced, would be informed by First Peoples' theoretical frameworks and terms of reference. This was grounded in place-based knowledge and understanding: how responsibilities and knowledge are situated in, and produced via, the relational links between our law, land and people (Graham, 2008; Graham, 2014; Heckenberg, 2015).

\footnotetext{
${ }^{5}$ While no time constraints were placed on the deliberation and work of the Reference Committee, the research team were restricted by Griffith University's academic calendar and funding arrangements for research team staffing. The Reference Committee were able to develop the First Peoples' module within
} 
While the Reference Committee were comfortable with this approach, they reinforced the need to critically assess the content that was developed as well as its methods of inclusion. The Reference Committee wanted to ensure that they were not developing something that "reinforces colonial practices and perspectives" by simply providing "an add-on to Western knowledges". The goal was to avoid exactly the situation that Collins-Gearing and Smith describe as "an aestheticisation of Indigenous Australia, where only certain aspects of that culture are acceptable to the Western viewpoint or Australian nation" (2016, pp.160-162).

The Reference Committee was informed by a developed understanding and lived experience of the many issues discussed in the literature regarding earlier attempts at including First Peoples' knowledge and perspectives in higher education. These difficulties include the prevalence of simply adding content, that inclusion can be a form of enclosure (Tuck and Yang, 2012), that simplistic attempts at decolonisation do not often achieve anything substantive and that presenting complex histories and knowledge as simple generalisations can further reinforce the exclusions and violence experienced by First Peoples (Nakata et al, 2012; Howlett, Ferreira, Seini and Matthews, 2013; Collins-Gearing and Smith, 2016).

The Reference Committee set out to avoid these issues by planning in advance according to First Peoples' terms of reference, knowledge and perspectives. By discussing our purpose, asking ourselves what we were trying to achieve and by grounding ourselves in First Peoples' theoretical frameworks, we were able to ensure the development of the First Peoples' module was responsive to these issues. To achieve this, the Reference Committee produced a document that would guide our understanding of 'Indigenous knowledge', that would inform course material and would be used to communicate externally the basis of the project. It was important to be able to achieve three key things with this document. The first was expressing First Peoples' content in a way that was informed by Indigenous cultures and 
traditions. The second was appropriately addressing the complex and shared histories of colonialism in Australia and how these form part of First Peoples' knowledge. The third was to ensure that First Peoples' knowledge and perspectives were not presented in a simplistic or binary way that would "simply contest a destructive and imposed Western framework" (Nakata et al, 2010, p.125).

The Reference Committee was guided by Nakata's important concept of the "cultural interface" that discusses a series of progressive phases to help navigate the complex interaction of First Peoples with other knowledge systems (2007; 2017). Nakata's first phase focuses on “continuities”, developing knowledge about First Peoples' cultures, histories and traditions but avoiding the common trait of viewing Indigenous knowledge or culture as prehistoric or static (2007). The second phase focuses on an "unsettling" program that focuses on "Ruptures, Discontinuities and Convergences" (2007). This phase develops an understanding of colonial history and its impact, developing knowledge built on those Indigenous perspectives introduced in the first phase. The third phase, building on the earlier layered phases, is called "Navigating the Interface" (2007). This phase "gives expression to various tensions that emerge" and enables a deeper understanding of the "layered entanglements, accommodations, and adaptations of Western and Indigenous knowledge [that] have occurred over generations" (Nakata et al, 2014, pp.14-15). The Reference Committee worked with this approach and chose the narrative metaphor of weaving, rather than embedding or incorporating, to explain our approach to the inclusion of First Peoples' knowledge and perspectives.

Most importantly, the Reference Committee believed that weaving better illustrated what we were trying to achieve by including First Peoples' content in the CI course. The emphasis on weaving enabled the Reference Committee to go beyond simple inclusions and to avoid the First Peoples' module becoming a repetition of the very system that the 
Reference Committee was trying to address. This approach avoided pitting 'Western' philosophies and worldviews against First Peoples' knowledge and perspectives and enabled the Reference Committee to transform practice itself rather than confirming to 'normal' and established non-Indigenous knowledge and power relationships within higher education (Carlson and McGloin, 2013; Nakata et al, 2014; Carey, 2015).

\section{The First Peoples' Module}

Building on the First Peoples' knowledge document, a Woven Law approach and the work of the Reference Committee, the First Peoples' module was developed to implement this approach to the inclusion of First Peoples' knowledge and perspectives. The First Peoples' module included two distinct parts. The first was the addition of a specific lecture on First Peoples' theoretical frameworks and a second lecture that provided First Peoples' knowledge and perspectives on other key course topics such as 'community' and 'human rights'. The second part of the First Peoples' module was the addition of the specific First Peoples' module in the Study Guide and Workbook. This addition also included First Peoples' perspectives on other module components such as community and human rights.

As part of the CI course, students are provided with a Study Guide and Workbook. The guide is a self-paced learning module that includes key administrative and assessment information and a series of modules that follow the lecture content and program. The guide includes modules that explore personal and professional growth, social theories of community and community values, and human rights perspectives and how these all relate to and inform the community organisation sector. First Peoples' knowledge and perspectives is also now covered across all sections and importantly included as a stand-alone module.

The First Peoples' module comprises a variety of artefacts. In addition to having traditional lecture content such as recorded lectures and lecture slides made available online 
for students, the module also includes additional support material developed to enhance the module and student learning toward achievement of Graduate Attribute 5. This additional content was collated as part of documenting the research project as it progressed and is made available as a Resource Point for students who wish to expand their knowledge of First Peoples knowledge and perspectives beyond the lectures and module material.

Research committee meetings were filmed and recorded then transcribed, and First People members of the Research Committee were further interviewed separately about the project. ${ }^{6}$ Importantly, lecture content was written, prepared and delivered by members of the Reference Committee and the course content was written specifically to address the learning outcomes of the course with a focus on contextualising and understanding First Peoples' history and place within Australian society, but with a view to having a wider application within other disciplines. ${ }^{7}$

Assessment for the course was also adapted to include elements of First Peoples relational responsibilities and obligations such as the Peer Discussion. Students are required to share reflections and learnings from their internships in collaborative groups with peers. Students also submit a written piece and evaluate each other's learning development. The Peer Discussion gives students a chance to come together to discuss their activities within a small group of other students in an informal discussion, but one that carries substantive pedagogical weight and is valued as such by the assessment requirements. A guideline for the discussion is provided to students to enable each student to obtain value from being able to share their internship activities and results with one another and to benefit from hearing each other share development experienced in their volunteering role. Importantly, the Peer

\footnotetext{
${ }^{6}$ This recording was conducted with the consent of participants and according to cultural protocols that required content to be reviewed and approved by members of the Reference Committee.

${ }^{7}$ See note 1 above for a description of the course learning outcomes and Graduate Attribute 5.
} 
Discussion provides a practical opportunity for the students to experience place-based knowledge and to have to work within and according to the attending responsibilities and obligations that result from this environment. The final piece of assessment requires students to submit a portfolio that includes a critical reflection analysing their experience through one of the social theories examined within the course, including having available to them the First Peoples module.

The content developed for students emphasised that key to understanding First Peoples' theoretical frameworks is understating how they are informed and produced by the key relational links between law, land and people (Kwaymullina, 2005; Kwaymullina and Kwaymullina, 2010; Maduro, 2012). Like any other culture and tradition, First Peoples' theoretical frameworks are worldviews that inform the way that First Peoples produce and understand knowledge about themselves and the world that they live in. Aboriginal scholar Karen Martin describes these frameworks as being informed by First Peoples' epistemologies and ontologies of "Ways of Knowing, Ways of Being and Ways of Doing" (2003, p.208). Underpinning these ways of knowing, being and doing are the foundational laws - or creation stories and dreaming - of First Peoples, gifted to them by their ancestors and embedded in the land and waters that First Peoples live in relation with.

Aboriginal scholars Ambelin and Blaze Kwaymullina further explain the relation of these elements of "Aboriginal philosophy [as] a pattern comprised of other patterns, of systems inside systems" (2010, p.196). Key to understanding these theoretical frameworks is understanding that everything is "interrelated and interdependent". This relational basis of First Peoples' philosophy forms the basis of life itself and was represented as the core of the First Peoples module, informing all Indigenous knowledge and perspectives.

Students were further engaged in these frameworks through lectures delivered by Indigenous members of the project team. These lectures emphasised an understanding of 
Indigenous knowledges as different, but not irreconcilable, to the predominant Western approaches to knowledge production and being that establish a split between mind and body, or nature and culture, to establish meaning and understanding of life (Graham, 2008; Graham, 2014). By understanding this, students were encouraged to focus on the interrelated reality of place - often described as country - and being from a First Peoples' philosophical point of view (Graham, 2008; Graham, 2014; Heckenberg, 2015). This means that rather than separating self from the world in order to produce objective knowledge about the world or self, students are encouraged to understand First Peoples' knowledges and understandings as being formed fundamentally in the relation of each element to the other. Mary Graham further explains this process: "Aboriginal logic maintains that there is no division between the observing mind and anything else: there is no 'external world' to inhabit. There are distinctions between the physical and the spiritual, but these aspects of existence continually interpenetrate each other" (2008, p.189).

\section{Student impact}

In order to assess student impacts and perceptions and the success of the project enabling students to achieve course outcomes and Graduate Attribute 5, the CI cohort were surveyed following their completion of the inaugural First Peoples' module. Of the 198 students who participated in the module, 127 surveys were completed. 91 of these students were undertaking the $\mathrm{CI}$ course as an elective, 22 students as a recommended course, and 13 students as a mandatory core subject. The sample consisted of 94 domestic (Australian) students and 33 international students. The students came from a range of disciplines with most students coming from Business and Health, although Arts, Education and Law were also well-represented. 
Students were asked to rate their awareness of First Peoples before the module, with $75 \%$ of students rating their awareness as either 'Low' or 'Neutral'. Survey responses following the completion of the teaching period indicate that the material was well received and significantly assisted students in achieving their learning outcomes and Graduate Attribute 5. Following the module, 59\% of respondents said their knowledge of First Peoples had improved. More specifically, $82 \%$ of respondents agreed that the inclusion of the First Peoples' content helped them achieve Graduate Attrribute 5, enabling them to be culturally capable when working with First Australians. This response was higher, at 87\%, when those students had been previously exposed to First Peoples' content.

These encouraging results indicate that reinforcement of First Peoples' content across the curriculum is important and effective in improving the cultural competence of students. This conclusion is further supported by the survey results with $71 \%$ of respondents agreeing that First Peoples' content should form part of their formal curriculum. While more research is needed, these promising results indicate an appreciation and identified need for more cohesive First Peoples' content woven throughout the broader curriculum. The Community Partners are important members of the CI course team and providing resources and opportunity for student development throughout the CI course. Beyond consistent positive feedback from the Community Partners regarding the benefit of students to their organisations, no data was collected from the Community Partners specifically addressing the First Peoples' Module. This information has however been identified as a possible point of reference for further data collection and evaluation.

\section{Conclusion}

Woven Law represents a promising framework for appropriately guiding the inclusion of First Peoples' knowledge within the university curriculum. Given the complexities associated with 
attempts to 'add' or 'embed' First Peoples' knowledge within Western knowledge frameworks, a new approach was sought. Establishing a First Peoples’ Reference Committee created space for First Peoples to lead the decision-making processes around the design of the course and delivery of the CI course.

Woven Law emerged as a promising framework to encourage students to build deeper understandings of other peoples and their selves through critical, reflexive, and dialogical encounters with First Peoples' knowledge and perspectives. By including and teaching First Peoples' knowledge through weaving, the Reference Committee was able to ensure that the practice and learning of First Peoples' knowledge continues in a way that is respectful and uncompromised.

The final result of this careful weaving was the First Peoples' module within the CI course. The student response to the First Peoples' module was predominantly positive, with a high percentage of students reflecting on their improved knowledge of First Peoples. Furthermore, almost $75 \%$ of the cohort agreed that First Peoples' content should be included in their formal curriculum. While there are limitations to this data set, namely that students were asked to self-reflect on their learning and data for evaluation was not collected from the Community Partners, these initial results indicate an appreciation for the importance of closely weaving First Peoples' knowledge within courses. Future research aims to explore how a Woven Law approach might be expanded to other aspects of the curriculum and courses. 


\section{References}

Battiste M and Henderson JY (2009) Naturalizing Indigenous Knowledge in Eurocentric Education. Canadian Journal of Native Education, 32(1), 5.

Biana H (2017) Ways of Weaving: Integrating Philippine Indigenous Philosophy and Art.

Paper presented at the Arts and Culture: Heritage, Practices and Futures Conference, Manila. Black CF (2011) The Land is the Source of the Law: A Dialogic Encounter with Indigenous Jurisprudence. London, United Kingdom: Routledge Cavendish.

Carey M (2015). The limits of cultural competence: an Indigenous Studies Perspective.

Higher Education Research \& Development, 34(5), 828-840.

Carlson B and McGloin C (2013) Indigenous Studies and the Politics of Language. Journal of University Teaching \& Learning, 10(1).

Collins-Gearing B and Smith R (2016) Burning Off: Indigenising the Discipline of English. The Australian Journal of Indigenous Education, 45(2), 159-169.

Gilbert S and Tillman G (2017) Teaching Practise Utilising Embedded Indigenous Cultural Standards. The Australian Journal of Indigenous Education, 46(2), 173-181.

Giovanangeli A and Snepvangers K (2016). Spaces of multiplicity: Rethinking indigenous perspectives in Australian tertiary education through altering teacher beliefs and practices. Commonwealth Essays and Studies, 38(2), 39.

Graham M (2008) Some Thoughts about the Philosophical Underpinnings of Aboriginal Worldviews. Australian Humanities Review, 45(45), 181-193.

Graham M (2014) Aboriginal notions of relationality and positionalism: a reply to Weber. Global Discourse, 4(1), 17-22.

Grieves V (2008) Aboriginal Spirituality: A Baseline for Indigenous Knowledge's Development in Australia. The Canadian Journal of Native Studies, 28(2), 363-398. 
Heckenberg R (2015) Learning in Place, Cultural Mapping and Sustainable Values on the Millawa Billa (Murray River). The Australian Journal of Indigenous Education 45(1), 1-10. Henderson JH (2005) Insights on First Nations Humanities. The Australian Journal of Indigenous Education, 34, 143-151.

Hollinsworth D (2013). Forget Cultural Competence; Ask for an Autobiography. Social Work Education, 32(8), 1048-1060.

Howlett C, Ferreira J, Seini M and Matthews C (2013) Indigenising the Griffith School of Environment Curriculum: Where to From Here? The Australian Journal of Indigenous Education, 42(1), 68-74.

Ingold T (2000) Perception of the Environment: Essays on Livelihood, Dwelling and Skill. London: Routledge.

Kwaymullina A (2005) Seeing the Light: Aboriginal Law, Learning and Sustainable Living in Country. Indigenous Law Bulletin, 6(11), 12-15.

Kwaymullina A (2016) Research, Ethics and Indigenous Peoples. AlterNative, 12(4), 437449.

Kwaymullina A and Kwaymullina B (2010) Learning to Read the Signs: law in an indigenous reality. Journal of Australian Studies, 34(2), 195-208.

Maduro O (2012). An (Other) invitation to epistemological humility: Notes toward a selfcritical approach to counter-knowledges. In Isasi-Daz AM and Mendieta E (eds) Decolonizing epistemologies: Latina/o theology and philosophy. Fordham University Press, pp. $87-106$.

Martin K and Mirraboopa B (2003) Ways of knowing, being and doing: A theoretical framework and methods for indigenous and indigenist re-search. Journal of Australian Studies 27(76), 203-214. 
McKnight A (2016) Meeting country and self to initiate an embodiment of knowledge:

Embedding a process for aboriginal perspectives. The Australian Journal of Indigenous Education, 45(1), 11-22.

Mignolo WD (1999) I am where I think: Epistemology and the colonial difference. Journal of Latin American Cultural Studies 8(2), 235-245.

Mignolo WD (2011) Decolonizing Western Epistemology / Building Decolonial Epistemologies. In Isasi-Daz AM and Mendieta E (eds) Decolonizing epistemologies:

Latina/o theology and philosophy. Fordham University Press, pp. 19-43.

Nakata M (2007) The cultural interface. The Australian Journal of Indigenous Education 36(S1), 7-14.

Nakata M (2007) Disciplining the Savages, Savaging the Disciplines. Canberra, ACT: Aboriginal Studies Press.

Nakata M (2018). Difficult Dialogues in the South: Questions about Practice. The Australian Journal of Indigenous Education 47(1), 1-7.

Nakata M, Nakata V, Keech S and Bolt, R. (2012). Decolonial goals and pedagogies for Indigenous studies. Decolonization: Indigeneity, education \& society, 1(1).

Nakata M, Nakata V, Keech S and Bolt R (2014) Rethinking Majors in Australian Indigenous Studies. The Australian Journal if Indigenous Education, 43(1), 8-20.

Pridham B, Martin D, Walker K, Rossengren R and Wadley D (2015) Culturally Inclusive Curriculum in Higher Education. The Australian Journal of Indigenous Education 44(1), 94105.

de Oliveira Andreotti V, Stein S, Ahenakew C and Hunt D (2015) Mapping interpretations of decolonization in the context of higher education. Decolonization: Indigeneity, Education \& Society 4(1), 21-40. 
Rigney LI (2012). Review of Indigenous Higher Education Consultancy: Indigenous Higher Education Reform and Indigenous Knowledges. Report commissioned for the Review of Higher Education Access and Outcomes for Aboriginal and Torres Strait Islander People. Available from https://docs.education.gov.au/documents/indigenous-higher-education$\underline{\text { reform-and-indigenous-knowledges }}$

Riley L, Howard-Wagner D and Mooney J (2015). Kinship online: Engaging 'Cultural praxis' in a teaching and learning framework for cultural competence. The Australian Journal of Indigenous Education 44(1), 70-84.

Russell L (2005). Indigenous knowledge and archives: accessing hidden history and understandings. Australian academic \& research libraries, 36(2) 161-171.

Smith LT (2012) Decolonizing Methodologies: Research and Indigenous Peoples. London, United Kingdom: Zed Books.

Tjanpi Desert Weavers (2015) Paarpakani: Take Flight. Cultural Studies Review 21(1), 149174.

Tuck E and Yang KW (2012) Decolonization is not a metaphor. Decolonization: Indigeneity, Education \& Society 1(1), 1-40.

Universities Australia (2011). National Best Practice Framework for Indigenous Cultural Competency in Australian Universities. Available from

http://www.universitiesaustralia.edu.au/ArticleDocuments/376/National\%20Best\%20Practice \%20Framework $\% 20$ for $\% 20$ Indigenous $\% 20$ Cultural $\% 20$ Competency $\% 20 \mathrm{in} \% 20$ Australian $\%$ 20Universities.pdf.aspx

Universities Australia (2017). Indigenous Strategy 2017-2020. Available from https://www.universitiesaustralia.edu.au/Media-and-Events/submissions-and$\underline{\text { reports/Indigenous-Strategy/Indigenous-Strategy-2017-2020 }}$ 
Watson I (2014) Raw Law: Aboriginal Peoples, Colonisation and International Law. London, United Kingdom: Routledge. 